\title{
Supervivencia de células fibroblásticas humanas en ausencia de suplementación
}

\author{
Survival of Human Fibroblastic Cells in the Absence of Supplementation \\ Víctor Simancas-Escorcia ${ }^{1}$, Antonio Díaz-Caballero ${ }^{2}$, Clara Vergara Hernandez ${ }^{3}$ \\ Institución donde se realizó el estudio: Universidad de Cartagena.
}

\section{Resumen}

Introducción. Los fibroblastos gingivales (FGs) son células del tejido conjuntivo gingival que han tomado en los últimos ańos una relevancia promisoria por su probable utilización en la terapia celular, dadas sus capacidades de multipotencialidad y de autorrenovación. Objetivo. Conocer y describir el impacto de la ausencia en la suplementación de Suero Fetal Bovino (SFB) en la supervivencia de fibroblastos gingivales en cultivos. Materiales y métodos. Fibroblastos gingivales fueron aislados de tejido gingival de pacientes sanos y cultivados en medios de cultivos DMEM (Dulbecco's Modified of Eagle Medium) en ausencia y suplementados con $0.2 \%$ de $\mathrm{SFB}$ a $37^{\circ} \mathrm{C}$ en una atmósfera húmeda con $5 \%$ de CO2. Se llevó a cabo una evaluación morfológica, de supervivencia y proliferación de los FGs, así como la identificación mediante la técnica de inmunofluorescencia de marcadores del citoesqueleto celular como la actina y mitocondrias. Resultados. Los FGs cultivados en ausencia y con suplementación de $0.2 \%$ de SFB evidenciaron una forma fusiforme, con núcleos ovalados y numerosas prolongaciones citoplasmáticas durante el tiempo de cultivo. Un leve aumento en la proliferación de FGs fue observado en aquellas células en contacto con el medio DMEM+0.2\% de SFB comparadas con el medio donde estuvo ausente la suplementación. El inmunomarcaje de la actina y las mitocondrias dejó en evidencia que la ausencia y suplementación a $0.2 \%$ de SFB no afectó su localización en los FGs evaluados.

\footnotetext{
1. Investigador del Grupo Interdisciplinario de Investigaciones y Tratamientos Odontológicos Universidad de Cartagena (GITOUC), Facultad de Odontología, Universidad de Cartagena, Colombia.

ORCID: http://orcid.org/0000-0003-0910-030X

2. Investigador del Grupo Interdisciplinario de Investigaciones y Tratamientos Odontológicos Universidad de Cartagena (GITOUC), Facultad de Odontología, Universidad de Cartagena, Colombia.

ORCID: http://orcid.org/0000-0001-9693-2969

3. Investigador del Grupo Interdisciplinario de Investigaciones y Tratamientos Odontológicos Universidad de Cartagena (GITOUC), Facultad de Odontología, Universidad de Cartagena, Colombia.

ORCID: http://orcid.org/0000-0002-6834-813X

Correspondencia: vsimancasescorcia@hotmail.com
} 
Conclusión. Los fibroblastos gingivales sobreviven y proliferan en ausencia de SFB, conservando sus características morfológicas celulares.

Palabras claves: (Decs Bireme): Fibroblastos, Encía, medio de cultivo libre de suero, Proliferación celular, Citoesqueleto de actina, Mitocondrias.

\section{Abstract}

Introduction. Gingival fibroblasts (GF) are cells of gingival connective tissue that have taken promising relevance in recent years due to their probable use in cell therapy, given their multipotencial and self-renewal capabilities. Objective. To know and to describe the impact of the absence of Fetal Bovine Serum (FBS supplementation on the survival of gingival fibroblasts in cultures. Materials and methods. Gingival fibroblasts were isolated from gingival tissue of healthy patients and cultured in DMEM (Dulbecco's Modified of Eagle Medium) culture media in absence and supplemented with $0.2 \% \mathrm{FBS}$ at $37^{\circ} \mathrm{C}$ in a humid atmosphere with 5\% CO2. A morphological evaluation, survival and proliferation of GF were carried out, as well as the identification by the immunofluorescence technique of cellular cytoskeleton markers such as actin and mitochondria. Results. The GF grown in the absence and with supplementation of $0.2 \%$ FBS showed a fusiform shape, with oval nuclei and numerous cytoplasmic extensions during the culture time. A slight increase in the proliferation of GF was observed in those cells in contact with the DMEM medium $+0.2 \%$ FBS compared to the medium where the supplementation was absent. Immunostaining of actin and mitochondria showed that the absence and supplementation to $0.2 \%$ of FBS did not affect its location in the evaluated. Conclusion. Gingival fibroblasts survive and proliferate in the absence of FBS, preserving their cellular morphological characteristics.

Keywords: (Mesh Database): Fibroblasts, Gingiva, Culture Media Serum-Free, Cell Proliferation, Actin Cytoskeleton, Mitochondria.

\section{Introducción}

A pesar de los desafíos bioéticos, la utilización de células humanas que pretenden ser utilizadas con fines terapéuticos ha ganado mucho espacio en los últimos años. Hoy por hoy, la obtención de un número suficiente de células capaces de generar satisfactoriamente una regeneración, luego de haber sido aisladas in vitro y amplificadas para ser trasplantadas en sitios anatómicos específicos, es un aspecto prioritario a resolver. Múltiples ensayos clínicos desarrollados en la actualidad ponen en evidencia la necesidad de 
grandes cantidades de células con propósitos terapéuticos $(1,2)$.

La obtención de un óptimo crecimiento en cultivos celulares in vitro y de las cantidades requeridas, manteniendo las características fenotípicas de las células, sus funciones y su estado de diferenciación dependen de ambientes de cultivo capaces de imitar aquellas encontradas en las condiciones fisiológicas in vivo e in situ. Estos entornos deben considerar elementos fundamentales como la temperatura, el $\mathrm{pH}$, oxígeno y la osmolaridad (3). El medio ambiente donde se desarrollan las células en cultivo debe contar con un soporte celular (caja de Petri), que gracias a sus condiciones especiales de revestimiento, permitirán la fijación y el buen desarrollo de las células.

Por su parte, el medio de cultivo es el responsable de proporcionar todos los tipos de moléculas solubles, nutrientes, hormonas, factores de crecimiento y suplementos necesarios para las células (4). El suplemento de los medios de cultivos más comúnmente utilizado es el Suero Fetal Bovino (SFB). El SFB es un componente esencial en la proliferación y la diferenciación de las células, incluidas las humanas. Este suplemento se obtiene de la sangre colectada a partir de punciones cardiacas de fetos bovinos luego de su nacimiento $(5,6)$. Son varias las funciones del SFB, entre ellas, proporcionar hormonas, proteínas, factores de estabilización y detoxificación necesarias para la células, así como factores de crecimiento activadores de los complejos de transcripción (7).
Un tipo celular prometedor en la terapia de diversas patologías humanas son los fibroblastos gingivales (FGs), principales células del tejido conjuntivo gingival, que por su plasticidad y actividad inmunomoduladoras son bastantes útiles en la terapia celular; gracias, además, a la facilidad técnica para su aislamiento y proliferación (8). Aunado a ello, recientemente se ha establecido que una población de FGs presentan características de multipotencialidad y autorrenovación prometedoras en la terapia celular (9). Probablemente sea esta la razón por la cual los FGs llevan cabo un proceso reparador de heridas más rápido cuando se compara con fibroblastos de otros tejidos.

Aunque el SFB es usado tradicionalmente en las investigaciones, como todo producto de origen animal implica riesgos de xeno-inmunización y transmisión zoonótica en caso de ser usados con fines terapéuticos en humanos. Por ello, con el propósito de evaluar la supervivencia de FGs humanas en ausencia de SFB y avanzar en su uso terapéutico, es preciso conocer su comportamiento en estas condiciones; y en consecuencia, encontrar métodos de cultivos alternativos, económicos y éticos que no implique el uso de productos derivados de animales. El presente trabajo tiene como objetivo conocer y describir el impacto de la ausencia en la suplementación de SFB en la supervivencia de fibroblastos gingivales en cultivos. 


\section{Materiales y métodos}

\section{Obtención de tejidos}

Fibroblastos gingivales fueron aislados a partir de biopsias de donantes con buen estado de salud, mayores de 18 años, no fumadores ni bajo tratamiento farmacológico con antihipertensivos, anticonvulsivantes e inmunosupresores. Se admitieron pacientes sometidos a la extracción de dientes premolares por razones ortodónticas, previa autorización mediante firma de consentimiento informado y teniendo en cuenta las normas éticas establecidas en la Declaración de Helsinki.

\section{Cultivo celular}

Las células fueron cultivadas en cajas de Petri (Gosselin ${ }^{\mathrm{TM}}$ ) en dos medios de cultivo que contenían DMEM (Dulbecco's Modified of Eagle Medium) (1X) con Gluta- MAXTM (GibcoTM), 1\% de penicilina-estreptomicina $(10,000 \mathrm{U} / \mathrm{mL})$ (GibcoTM) y $0,5 \mathrm{de}$ Anfotericina B (GibcoTM). El medio de cultivo 1 (DMEM+SFB 0,2\%), contenía adicionalmente $0,2 \%$ de $S F B$ y, el medio de cultivo 2 (DMEM+SFB 0\%) se dispuso en ausencia de SFB. Las células fueron incubadas a $37^{\circ} \mathrm{C}$ en una atmosfera húmeda con $5 \%$ de $\mathrm{CO}_{2}$. Los medios de cultivos fueron cambiados cada 48 horas.

\section{Evaluación morfológica}

Se llevó a cabo un análisis morfológico a lo largo de 7 días utilizando un microscopio de contraste de fases donde fue observada la supervivencia y proliferación de las células fibroblásticas en ambos grupos de cultivo. Se evaluó la forma nuclear de los FGs mediante coloración del ADN, utilizando Hoechst 33342 (Thermo Fisher Scientific).

\section{Inmunofluorencia}

Se fijaron las células en $4 \%$ de paraformaldehído (Sigma-Aldrich ${ }^{\oplus}$ ), seguido de la permeabilización en una solución de $0.5 \%$ de Triton X-100 (Sigma-Aldrich ${ }^{\odot}$ ) y la incubación en una solución con $1 \%$ de BSA (Sigma-Aldrich $^{\odot}$ ) por $1 \%$ de glicina (Sigma-Aldrich ${ }^{\oplus}$ ) a temperatura ambiente. Posteriormente, las células fueron incubadas con los anticuerpos primarios durante toda la noche a $4^{\circ} \mathrm{C}$. Al día siguiente, las células estuvieron en contacto 2 horas a temperatura ambiente con el anticuerpo secundario. Previo montaje de las células en solución Immu-MountTM (Thermo Scientic), se procedió a la coloración de los núcleos mediante DAPI (Life Technologies Corporation). Como anticuerpo primario fue utilizado anti-TOMM20 (1:400). El anticuerpo secundario empleado fue Alexa Fluor 488 donkey anti-conejo (1:400). Los filamentos de actina fueron marcados mediante Alexa Fluor ${ }^{\text {TM }} 594$ Phalloidin (Thermo Fisher Scientific) durante 15 minutos de acuerdo a las recomendaciones del fabricante. Las observaciones fueron realizadas en el microscopio IXplore Pro (Olympus). 


\section{Resultados}

La supervivencia de los fibroblastos gingivales fue evaluada en cultivos celulares suplementados con $0.2 \%$ de SFB y en su ausencia. En las dos condiciones creadas los FGs mostraron aspectos microscópicos compatibles con la vida durante 7 días de cultivo celular. Los FGs presentaron una forma fusiforme y presencia de múltiples prolongaciones citoplasmáticas que permi- tieron el contacto entre los fibroblastos. Los FGs tuvieron un crecimiento diferencial en su proliferación de acuerdo a la suplementación con SFB. En la condición de cultivo 1 (DMEM+SFB $0,2 \%)$ se pudo observar una confluencia de células de alrededor $60 \%-70 \%$ posterior a 72 horas de cultivo, mientras que los FGs cultivados en ausencia de SFB presentaron una confluencia aproximada del 40\% durante el mismo periodo de tiempo (ver Figura 1).

Figura 1. Fibroblastos gingivales de 72 horas cultivados en presencia de SFB $0.2 \%$ (A) y ausencia de SFB (B). DMEM: Dulbecco's Modified of Eagle Medium. SFB: Suero Fetal Bovino. Barra blanca: $400 \mu \mathrm{m}$.
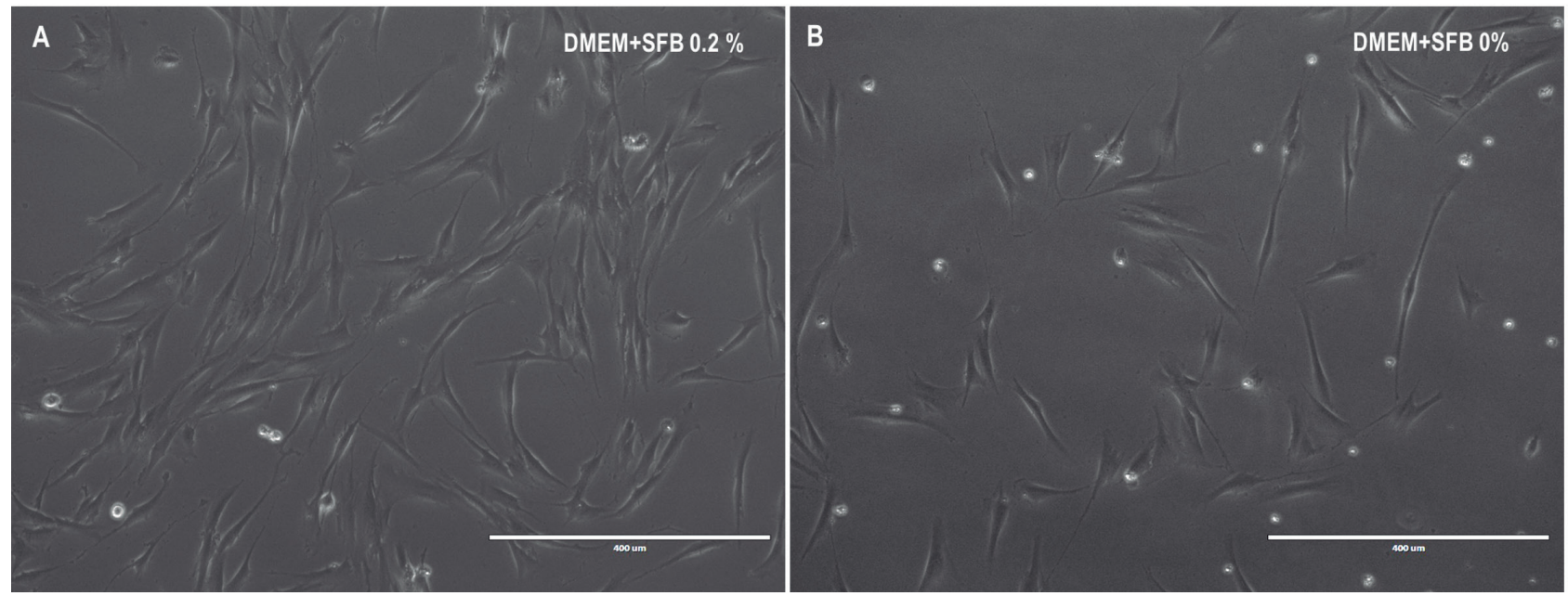

Fuente: Elaboración propia.

Al mismo tiempo, se pudo evidenciar la presencia de FGs con núcleos ovalados, bien definidos y distribuidos en el soporte del cultivo celular. Estas características fueron apreciables en los FGs cultivados en $0.2 \%$ de SFB y ausencia de este suplemento (ver Figura 2). Durante el tiempo de cultivo, se pudo constatar la presencia no cuantificable de numerosas células flotantes desde las primeras 24 horas, que fueron disminuyendo con el pasar de los días de cultivo celular. Estas observaciones fueron visibles en ambas condiciones evaluadas, pero fueron más marcadas en los FGs cultivados en ausencia de SFB. 
Figura 2. Núcleos de fibroblastos gingivales marcados con Hoechst cultivados en SFB 0.2\% (A) y SFB 0\%

(B). DMEM: Dulbecco's Modified of Eagle Medium. SFB: Suero Fetal Bovino. Barra blanca: $200 \mu \mathrm{m}$.

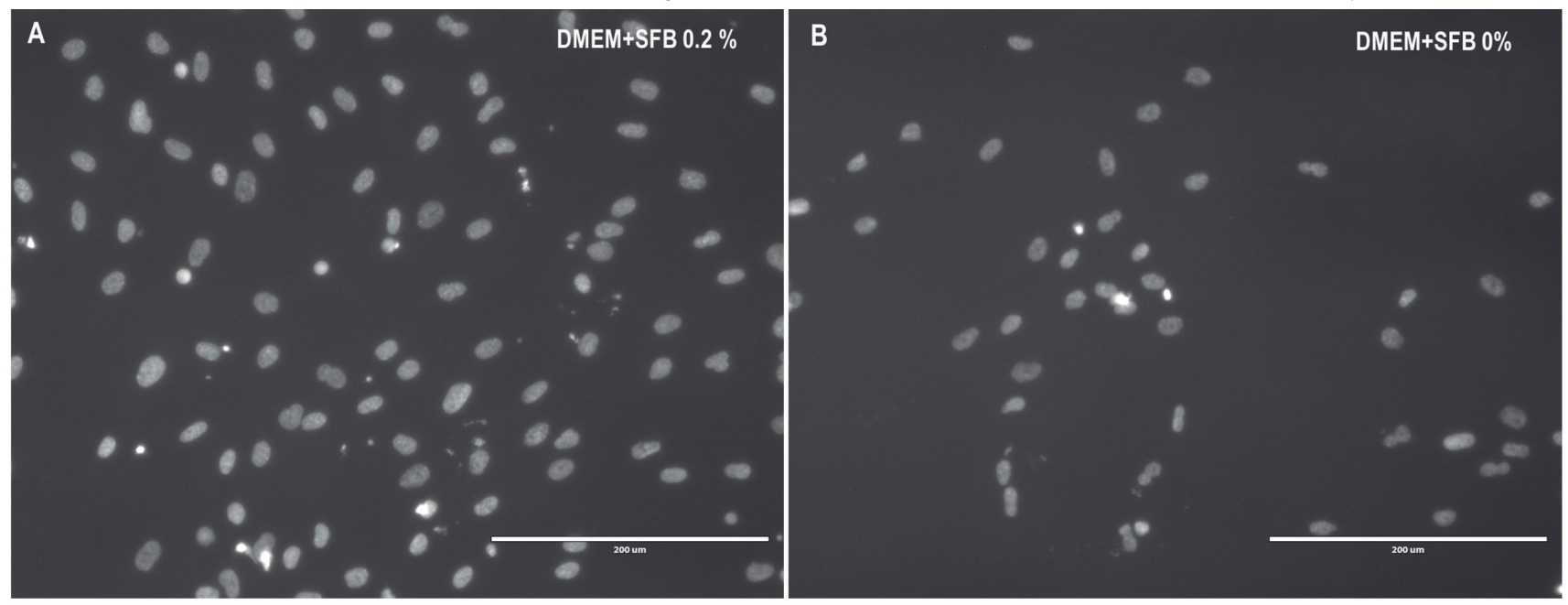

Fuente: Elaboración propia.

Posterior a 7 días de cultivo se identificó por medio de inmunofluorescencia la presencia de los filamentos de actina. La evaluación de un elemento esencial en la arquitectura del citoesqueleto de los FGs como es la actina, fue observada en aquellas células cultivas en $0.2 \%$ y ausencia de SFB. Se evidencia un número mayor de células con marcaje con la faloidina que exponen un contacto intercelular entre los FGs del grupo de células suplementadas con $0.2 \%$ de SFB en comparación con el grupo de FGs sin suplementación (ver Figura 3. A, D).
De manera similar, fue detectada la presencia de las mitocondrias en las dos condiciones de cultivos realizadas (ver Figura 3. B, E). El inmunomarcaje de estas organelas celulares fue muy similar en los FGs cultivados con $0.2 \%$ y ausencia de SFB. Tanto el marcaje de los filamentos de actina como de las mitocondrias mediante colocalización inmunofluorescente (ver Figura 3. C, F) permiten mencionar que no existe diferencias morfológicas en la localización de estos elementos celulares en los dos grupos analizados.

Figura 3. Identificación de los filamentos de actina (rojo) y mitocondrias (verde) de fibroblastos gingivales mediante la técnica de inmunofluorescencia. Doble marcaje: actina (faloidina)-mitocondrias (TOMM20) de fibroblastos gingivales en cultivo suplementado con SFB 0.2\% (A,B,C) y SFB 0\% (D,E,F). DMEM: Dulbecco's Modified of Eagle Medium. SFB:

Suero Fetal Bovino. Barra blanca: $200 \mu \mathrm{m}$.
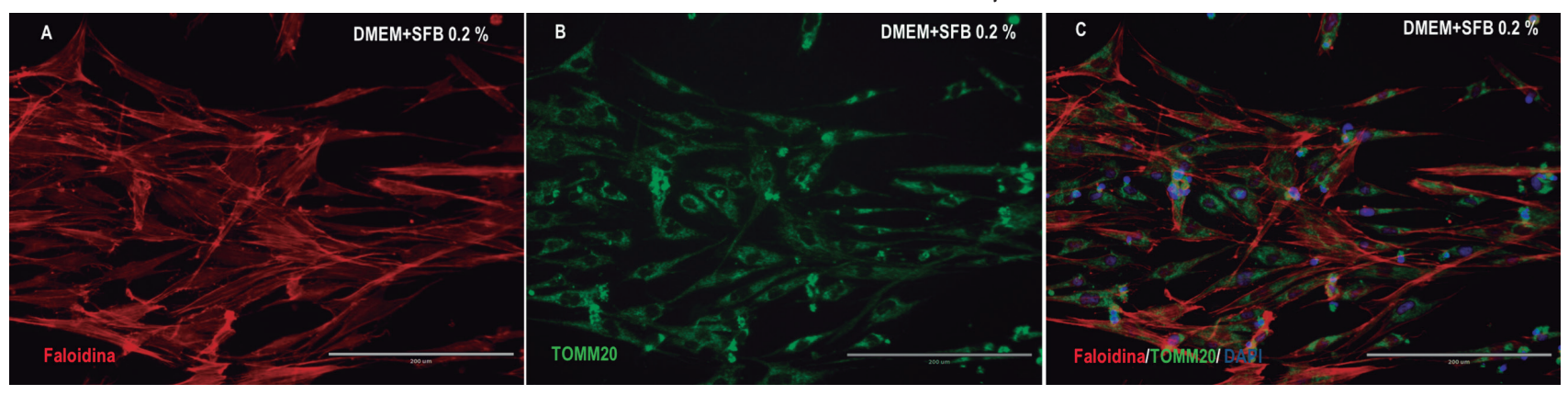


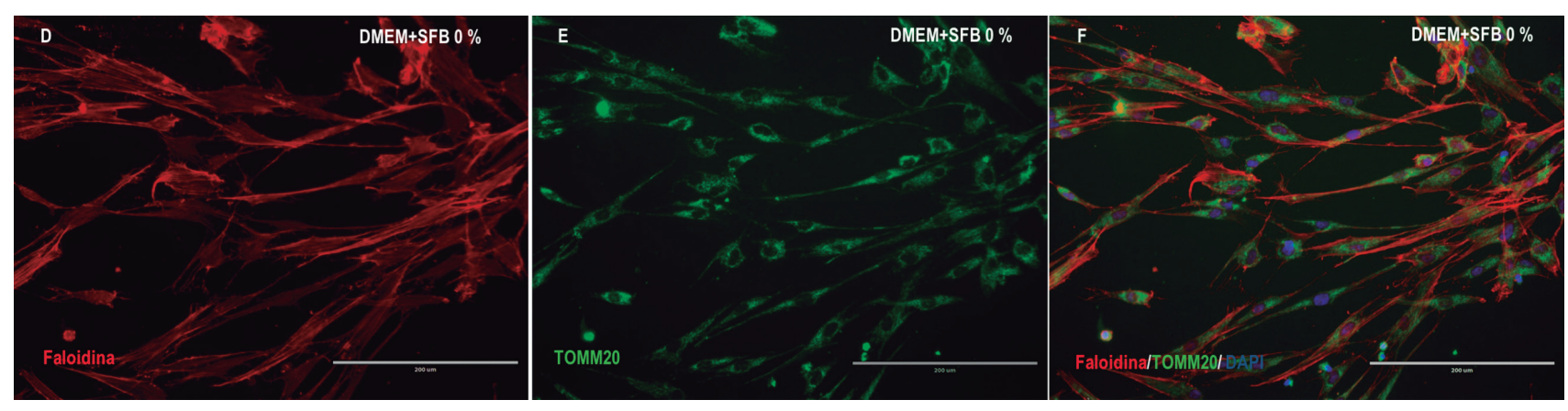

Fuente: Elaboración propia.

\section{Discusión}

Este estudio ha puesto en evidencia la supervivencia de los FGs humanos cultivados en ausencia de suplementación con SFB en un medio de cultivo. Cada vez más estudios similares al actual se interesan en la generación de cultivo de FGs humanos en ausencia de SFB debido a las variaciones encontradas lote a lote de este suplemento y a la inadecuada aplicación clínica de los FGs en humanos cuando se emplean productos de origen animal (10). Aunque el trabajo actual se limita al impacto de la concentración de SFB, es importante haber identificado que los FGs pueden llegar a ser cultivables en ausencia de SFB sin sufrir alteraciones morfológicas y probablemente funcionales.

La concentración diferencial de suplementación con SFB en los FGs permiten manifestar que la ausencia de este elemento es compatible con la supervivencia, aspectos morfológicos y probablemente funcionales de estas células. Los resultados obtenidos en el presente trabajo, junto aquellos de estudios recientemente publicados dan muestra de cómo el SFB afecta el rendimiento y proliferación de los cultivos celulares $(11,12)$. Por ello, con el propósito de hacer posible la proliferación de células y evitando la utilización de medios de cultivos suplementados con SFB, en los equipos de investigación en la actualidad, como el presente, se declara el deseo de orientarse en los laboratorios hacia los suplementos de medios de origen humanos, autógenos o alógenos, siempre que estos sean capaces de mostrar una efectividad igual o superior al SFB en la proliferación de FGs in vitro.

Los resultados expuestos permiten inferir que aunque en mínimas concentraciones, los aportes que puede brindar la suplementación con SFB proporciona los elementos necesarios para el óptimo desarrollo de los FGs, entre ellos, el factor de crecimiento epidérmico (EGF), factor de crecimiento derivado de plaquetas (PDGF) y factor de crecimiento de fibroblastos (FGF) (13). Han sido probablemente la ausencia de ellos y de otros componentes que han afectado el crecimiento celular cuando el SFB estuvo ausente. Sin embargo, sería intere- 
sante investigar cómo sustitutos del SFB, entre ellos, los derivados plaquetarios, son capaces de reemplazar estos elementos $y$ contribuir a condiciones de cultivo compatible con la terapia celular, como lo han demostrado estudios recientes (14-18).

La visualización de la distribución de la actina como proteína elemental en la formación del citoesqueleto que sirve como soporte de las organelas celulares, como las mitocondrias, identificadas en este trabajo, son resultados satisfactorios cuando se tiene en cuenta que los FGs fueron cultivados en ausencia o concentraciones muy bajas de SFB. Ello indicaría que al menos en un corto periodo de tiempo los FGs conservan sus estructuras morfo-funcionales. Sobre todo cuando se tiene presente que organelas como las mitocondrias participan en la supervivencia y proliferación celular gracias a la expresión coordinada de estas organelas con el núcleo (19). La identificación de la traslocasa de la membrana externa, subunidad 20 (TOM20) en FGs, hace ver que una proteína con elevado dinamismo conformacional y parte de la membrana externa mitocondrial, responsable del flujo de proteínas hacia el espacio intramembrana de la mitocondria (20) no se encuentra impactada por la disminución y/o ausencia del SFB.

Los resultados expuestos en el presente trabajo permiten aseverar que los fibroblastos gingivales son células que pueden sobrevivir en ausencia de la suplementación con SFB, conservando su morfología y organelas celulares como las mitocondrias.

\section{Agradecimientos}

Al programa Bolívar Gana con Ciencia de la Gobernación de Bolívar, Colombia y la Fundación Ceiba por el acompañamiento.

\section{Conflictos de intereses}

El manuscrito fue preparado y revisado con la participación de todos los autores, quienes declaramos que no existe ningún conflicto de interés que ponga en riesgo la validez de los resultados presentados.

\section{Referencias}

1. Park WS, Ahn SY, Sung SI, Ahn J-Y, Chang YS. Mesenchymal Stem Cells: The Magic Cure for Intraventricular Hemorrhage? Cell Transplantation. 2017;26(3):439-48. https:// doi:10.3727/096368916X694193

2. Subbanna PKT. Mesenchymal stem cells for treating GVHD: In-vivo fate and optimal dose. Medical Hypotheses. 2007 Jan 1;69(2):469-70. https:// doi:10.1016/j.mehy.2006.12.016

3. Phelan K, May KM. Basic Techniques in Mammalian Cell Tissue Culture. Current Protocols in Toxicology. 2016 Nov 1;70(1):A.3B.1-A.3B.22. https://doi:10.1002/cptx.13

4. Donaldson C, Bishop K. Cell culture. Br J Hosp Med. 2015 Jan 2;76(1):C2-5. https://doi:10.12968/ hmed.2015.76.1.C2

5. Alam MdE, Iwata J, Fujiki K, Tsujimoto Y, Kanegi R, Kawate N, et al. Feline embryo development in commercially available human media supplemented with fetal bovine serum. Journal of Veterinary Medical Science. 2019;81(4):629-35. https:// doi:10.1292/jvms.18-0335 
6. Jan van der Valk, Karen Bieback, Christiane Buta, Brett Cochrane, Wilhelm Dirks, Jianan Fu, et al. Fetal bovine serum (FBS): Past - present - future. ALTEX. 2018 Jan 17; 35(1). https://doi:10.14573/ altex. 1705101

7. Wei Z, Batagov AO, Carter DRF, Krichevsky AM. Fetal Bovine Serum RNA Interferes with the Cell Culture derived Extracellular RNA. Scientific Reports. 2016 Aug 9; 6:31175. https://doi:10.1038/ srep31175

8. Simancas-Escorcia V, Diaz-Caballero A. Fisiología y usos terapéuticos de los fibroblastos gingivales. Odous Cientifica. 2019; 20(1): 41-57. Disponible en: http://servicio.bc.uc.edu.ve/odontologia/revista/vol20n1/art05.pdf

9. Jin SH, Lee JE, Yun J-H, Kim I, Ko Y, Park JB. Isolation and characterization of human mesenchymal stem cells from gingival connective tissue. Journal of Periodontal Research. 2015;50(4):461-7. https:// doi: $10.1111 /$ jre. 12228

10. Castells-Sala C, Martorell J, Balcells M. A human plasma derived supplement preserves function of human vascular cells in absence of fetal bovine serum. Cell \& Bioscience. 2017 Aug 14;7(1):41. https://doi:10.1186/s13578-017-0164-4

11. Farzaneh M, Zare M, Hassani S-N, Baharvand H. Effects of various culture conditions on pluripotent stem cell derivation from chick embryos. Journal of Cellular Biochemistry. 2018;119(8):6325-36. https://doi:10.1002/jcb.26761

12. Azouna NB, Jenhani F, Regaya Z, Berraeis L, Othman TB, Ducrocq E, et al. Phenotypical and functional characteristics of mesenchymal stem cells from bone marrow: comparison of culture using different media supplemented with human platelet lysate or fetal bovine serum. Stem Cell Research \& Therapy. 2012 Feb 14;3(1):6. https://doi:10.1186/ scrt97

13. Brunner D, Frank J, Appl H, Schöffl H, Pfaller W, Gstraunthaler G. Serum-free cell culture: the serum-free media interactive online database. AL-
TEX. 2010;27(1):53-62. https://doi:10.14573/altex.2010.1.53

14. Freymann U, Metzlaff S, Krüger J-P, Hirsh G, Endres M, Petersen W, et al. Effect of Human Serum and 2 Different Types of Platelet Concentrates on Human Meniscus Cell Migration, Proliferation, and Matrix Formation. Arthroscopy: The Journal of Arthroscopic \& Related Surgery. 2016 Jun 1;32(6):1106-16. https://doi:10.1016/j.arthro.2015.11.033

15. Cowper M, Frazier T, Wu X, Curley LJ, Ma HM, Mohiuddin AO, et al. Human Platelet Lysate as a Functional Substitute for Fetal Bovine Serum in the Culture of Human Adipose Derived Stromal/ Stem Cells. Cells. 2019;8(7). https://doi:10.3390/ cells8070724

16. Pons M, Nagel G, Zeyn Y, Beyer M, Laguna $T$, Brachetti $T$, et al. Human platelet lysate as validated replacement for animal serum to assess chemosensitivity. ALTEX - Alternatives to animal experimentation. 2019 Apr;36(2):277-88. https:// doi:10.14573/altex.1809211

17. Carrera Páez, L. C., Pirajan Quintero, I. D., Urrea Suarez, M. C., Sanchez Mora, R. M., Gómez Jiménez, M., \& Monroy Cano, L. A. (2015). Comparación del cultivo celular de HeLa y HEp-2: Perspectivas de estudios con Chlamydia trachomatis. NOVA, 13(23). Disponible en: https://revistas.unicolmayor. edu.co/index.php/nova/article/view/284

18. Ordoñez Vásquez, A., Jaramillo Gómez, L., Ibata, M., \& Suárez-Obando, F. (2017). Técnica de Tinta China en células adherentes en cultivo. NOVA, 14(25), 9-17. Disponible en: https://revistas.unicolmayor.edu.co/index.php/nova/article/view/510

19. Richter U, Lahtinen T, Marttinen P, Myöhänen M, Greco D, Cannino G, et al. A Mitochondrial Ribosomal and RNA Decay Pathway Blocks Cell Proliferation. Current Biology. 2013 Mar 18;23(6):53541. https://doi:10.1016/j.cub.2013.02.019

20. Komuro Y, Miyashita N, Mori T, Muneyuki E, Saitoh T, Kohda D, et al. Energetics of the Presequence-Binding Poses in Mitochondrial Protein 
Import Through Tom20. J Phys Chem B. 2013

Mar 14;117(10):2864-71. https://doi:10.1021/

jp400113e 